\title{
From Citizenship to Queer Counterpublic: Reading Taipei's New Park
}

\author{
FRAN MARTIN
}

This paper focuses on the ways in which official narratives of the 'global city' in 1990s Taipei project models of sexuality which are negotiated and contested by gay and lesbian (tongzhi) activist practices and discourses. Analysing the densely symbolic site of Taipei's New Park and particularly the Democratic Progressive Party City Government's plans for its redevelopment (1995-96), the paper considers the tense relation which the liberal rhetoric of a space made newly 'public' bears to the sexually non-normative practices of male homosexual cruising which traditionally take place in New Park and the surrounding city block. Examining the City Government's liberal rhetoric on homosexuality (tongxinglian), the paper contrasts this rhetoric with the more conservative and overtly homophobic sexual politics espoused by other regimes in the region. It also attempts to unpack the logic that enables such a self-consciously 'tongzhi-friendly' administration nevertheless to continue harshly to discipline men who practise homosex in the newly 'public' spaces of the park and the street. Finally, the paper discusses some critical responses by tongzhi writers and activists to the City Government's rewriting of the 'public' and the 'private' for the new Taipei.

Keywords: homosexuality; lesbian and gay; globalisation; public/private; urban space

The official treatment of 'homosexuality' (tongxinglian) in 1990s Taiwan presents a marked contrast to its representation in other states within the region, such as the People's Republic of China and Singapore. In those states, strongly nationalist, anti-Western ideologies have been used in an attempt to justify official homophobia in the name of cultural nationalism [1]. In Taiwan, by contrast, the lifting of martial law in 1987 and the shift from authoritarian nationalist (KMT) rule toward the current democracy have been attended by wide-ranging political and social liberalisations. This has resulted in the 1990s in an apparent official embrace of liberal sexual politics, which stands in marked contrast to the highly conservative official constructions of tongxinglian during the martial law period (1949-87) [2]. During this same period, the local lesbian and gay (or tongzhi, a term which is discussed below) movement is attaining increasing visibility. The year 1990 saw the establishment of the first openly lesbian or gay organisation: the lesbian social and activist group Women zhi Fian (Between Us), and in 1993 the first publicly distributed lesbian 
or gay magazine was launched: the lesbian publication $A i$ Bao (Love Paper). Since then, tongzhi groups have been formed on university campuses island-wide, while commercial lesbian and gay subcultures become increasingly visible through bar and dance cultures and glossy 'lifestyle' magazines such as $G \mathcal{E} L$, established in 1996 [3]. The term 'tongzhi' has become, since its arrival in Taiwan Mandarin from Hong Kong in the early 1990 s, the term most commonly used to refer to something like 'lesbian and gay', appearing frequently in book, magazine, TV and film titles, and in the names of activist organisations [4]. Etymologically meaning 'same-will', tongzhi is the common translation of 'comrade' as in both CCP and KMT nationalist rhetoric, appropriated to mean something like 'lesbian/gay' partly because its first character is also the first of tongxinglian.

Despite the ostensible official embrace of gayness, the vigour of the nascent tongzhi movement, and the fact that 'homosexuality' is nowhere directly addressed in the legal code of the Republic of China on Taiwan, public homosexual behaviour continues to be policed under laws which designate it indirectly [5]. Such continuing persecution of men who practise public homosex stands in stark contradiction to the public avowal by various official figures in the 1990s of a liberal sexual politics and of support for the tongzhi movement. This contradiction marks an ideological disjuncture which this paper aims to explore further.

Perhaps the example best known to Western audiences of 1990s Taiwan's ostensible official embrace of 'gayness' is found in Ang Lee's 1993 gay-themed film The Wedding Banquet, which was the product of a co-operation between the KMT government-owned Central Motion Picture Corporation in Taiwan and Good Machine Production in the USA. President Lee Teng-Hui himself has congratulated Ang Lee for 'winning glory for Taiwan's people in the international arena' through his films, also expressing the hope that Lee might make further films which 'help more people in the international arena to understand Taiwan clearly' (Wu Guangzhong 1997: 4; Huang Wenzheng 1997: 22) [6]. Remarkably, the President cites the cinema of a director whose oeuvre includes a film depicting a homosexual relationship between a Taiwanese and an American man, as a laudable contribution to Taiwan's international cultural diplomacy. This appears to place the sexual and cultural politics of his regime at a near-unbridgeable distance from those, say, of Singaporean Foreign Minister Wong Kan Seng who remarked at the UN World Human Rights Conference, in the year of Wedding Banquet's release, that 'homosexual rights are a Western issue, and are not relevant to this conference' (quoted in Berry 1994: 73). As this example demonstrates, as well as being a period of social liberalisation in sharp contrast with the situation in the past and in other regimes in the region, the 1990s is also a period in which Taiwan's government seeks actively to reposition the island, culturally as well as economically, in relation to an explicitly transnational imaginary (a term taken from Wilson \& Dissanayake 1996). This paper aims to explore some of the ways in which the rise of such transnational imaginaries-both official and unofficial-conditions the representation and regulation of tongxinglian in the current period.

In what follows, I take the geographic and discursive site of Taiwan's capital, Taipei City, as the ground for my argument on the global/local nexus vis-à-vis sexual 
politics in 1990s Taiwan. The paper includes a case study of a conflict between the Democratic Progressive Party (DPP) Taipei City Government (1994-98) and local tongzhi activists, over the meanings of Taipei's New Park-Taiwan's best known gay male cruising area [7]. Through this example, the paper poses questions which include: with the wane in power of authoritarian Chinese nationalism in Taiwan and the privileging of 'democracy', does tongxinglian, in contrast to its abjection in other states in the region, always in fact find itself the subject of unreserved official approval? If not, what can be learned about the relationship between Taiwan's ascendant liberal cultural politics and the regulation of sexuality, from the particular instances in which tongxinglian continues to occasion official anxiety? What novel possibilities, and what new constraints, attend local productions of sexuality in this era of intensified transnationalisation of economy and culture in Taiwan? In particular, I examine the effects for the regulation of homosexuality, of the reconfiguration of the categories 'public' and 'private' as a result of the reorganisation of urban and social space in 1990s Taipei.

\section{Sexuality and the 'Global City'}

The first popularly elected City Government after years of KMT appointments, Chen Shuibian's administration (1994-98) took on the project of reimagining crucial aspects of Taipei City with the mutually reinforcing goals of making it both an 'international' city, and also a 'city for the citizens' (shimin chengshi). This was a doubled strategy, then, of globalisation and localisation, and was styled by Chen, with his characteristic populism, as a plan toward a 'happy hopeful Taipei City' (xiwang kuailede Taibei Shi) (see You Changshan 1998). Central among the City Government's projects toward the symbolic rebuilding of Taipei as global city was the project titled 'Preserving the Historical Capital District', previously the militarised and restricted Bo'Ai Special District. Chen was defeated at the 1998 mayoral election by KMT candidate Ma Yingiiu, and most of his plans to redevelop this central district have not been realised [8]. However, the conflicts arising as a result of the proposal are worth examining insofar as they illuminate broader questions about the relationship between the transformation of urban space in globalising cities, and the production of sexuality-questions which have continuing relevance to theorising the reconfiguration of Taiwan's public cultures at the end of the 1990s. Furthermore, given that since 1998 Chen Shuibian has advanced from his position as Mayor of Taipei City to that of DPP candidate for Taiwan's presidency at the year 2000 election, it is particularly interesting to examine the ideological basis of his mayorship, since this ideology underwrites what is now Taiwan's non-KMT, liberal political mainstream.

The following passage appears in the 1996 White Paper produced by Taipei's Department of Urban Development as the preface to an account of that year's competition to redesign the Presidential Square area:

Located in the historical Capital District, the major landmark of the Presidential Palace, constructed in 1919, has for a long time been a 
paradigmatic symbol of centralised political power. Because of its history, this space has always given a tense impression of heavily-guardedness and political sloganeering; as the territory of guards and security personnel, the carpark which occupies the main square makes the Palace distant and unreachable to the people, which is a great pity.

With the gradual process of political liberalisation, the people have begun to demand the 'lifting of spatial martial law' [kongiian jieyan]. [...] in 1996 the Urban Development Bureau launched the Competition to Redesign the Presidential Square, in order that this space be completely returned to the rightful usage of the people, making 'Taipei City' a focus of international attention and bettering the image and status of the city. (Taipei City Government 1996: 54)

This passage neatly expresses some of the major concerns of Chen's government which are played out on the discursive site of the former Bo'Ai Special District: internationalisation, populism, and a sharp differentiation from old-style KMT politics. In opposition to that of the martial law period, Chen promises urban space freed of the tension created by symbols of the centralised power of the KMT (security guards; political slogan banners). Creating public as opposed to militarised space and opening the city up to 'the people', his government promises a liberalisation of urban space comparable to the broader political liberalisations following the lifting of martial law. However, given that New Park and its surrounds are notorious island-wide and beyond as Taiwan's best-known gay cruising area, the question of the district's redevelopment becomes significantly more complex than is suggested by this apparently straightforward desire to build over oppressive memory with the hope and happiness of the modern, democratic capital city.

Unsurprisingly, perhaps, the City Government's rhetorics of democratisation include an ostensible support for 'sexual liberalisation' in a willingness to support 'gay rights'. In the first issue of the glossy gay magazine $G \mathcal{E} L$ in 1996 , the DPP published a message of support for tongzhi equality, liberation and rights, proclaiming itself 'the tongzhi's tongzhi', or 'the gay person's comrade' (GEL 1996: 1). As Cindy Patton (forthcoming) has observed on a state level in Taiwan, such public support for 'minority rights' can act symbolically to distance the supposedly 'modern, liberal' state of contemporary Taiwan from its implied other, the 'repressive' PRC. In the case of the DPP's publicly tongzhi-friendly stance, though, the implied 'other' is also the old-style conservative faction of the KMT from which the DPP now sets itself apart by its embrace of liberal humanism and minority rights discourses.

Given Chen's government's stated desire to forge stronger links with tongzhi communities, the protests of tongzhi groups over the plans to redesign the New Park area must have been disheartening to his administration (Lin Shuling 1996b). Following the announcement of the plans for the area in October 1995, the Tongzhi Space Alliance (Tongzhi Kongiian Xingdong Zhenxian) was formed in December of that year by concerned students and activists, some of whom were already involved in other areas of the tongzhi movement. In February 1996, Xie Peijuan, a 
spokeswoman for the Alliance, wrote under the heading 'Hopeful, Happy, Heterosexual':

Often, so-called urban renewal amounts simply to throwing various disadvantaged groups out of the social centre, and the renewal plan for the Bo'Ai Special District put forward by the Taipei Municipal Government would do just that. In the name of urban renewal, it would expell tongzhi from New Park and from the Central District of Taipei City. When Taipei City's Mayor imagines a 'happy, hopeful' city, he clearly doesn't see any tongzhi within it; the sort of space [which he imagines] has no place for tongzhi. (Xie Peijuan 1996: 89-90)

This argument, representative of the Alliance's position, understands Chen's government and the sort of Taipei City envisioned in its planning policies as inherently homophobic: it pits 'tongzhi rights' against 'heterosexual power' so that the dominant distinguishing factor between the kinds of sexuality allowable in Chen's Taipei and those not allowable, is ultimately the gender of sexual object choice. Yet, given Chen's and the DPP's efforts to distinguish themselves precisely by embracing tongzhi rights discourses, I would suggest that there is something more complex going on than a straightforward rejection of homosexuality per se. This is particularly the case in the light of the administration's extraordinary and unprecedented in-principle agreement in 1996 to provide a publicly funded tongzhi club to compensate for the loss of New Park (Lin Shuling 1996a).

Zhang Jingsen, the Director in 1996 of the Department of Urban Development, makes a more telling analysis of his department's stance on homosexual cruising in New Park than that of the Alliance, in a statement suggesting that the proposed tongzhi club might be better located elsewhere than in New Park. Zhang notes that owing to their 'differing social backgrounds', different groups of homosexuals favour very different kinds of public space: while the gay bars of affluent eastern Taipei are frequented largely by white-collar workers, those who gather in New Park are predominantly 'students, the unemployed, and a small number of foreign nationals' (Zhang Jingsen quoted in Lin Shuling 1996a). Rather than opening a tongzhi club on the New Park site, Zhang expresses his department's desire to find a more 'appropriate' place for such a club-presumably in a more upmarket neighbourhood. Although the City Government's plans for a publicly funded gay club turned out to be short-lived, it seems clear from Zhang's initial embrace of such a plan that what bothered the administration was not the non-normativity of 'homosexuality' as distinct from a proper 'heterosexuality', but rather the public displays of sexual behaviour in the park by the economically distinguished class of 'students and the unemployed': that is, the visibility of certain non-consumptive forms of sexual behaviour in spaces now designated as 'public spaces for Taipei's citizens'. The proper citizen of the imagined modern, democratic city of Taipei, in other words, is not necessarily a 'heterosexual' one, but $i$ defined by certain indicatively middle-class leisure and consumption practices. In this sense, the rhetoric of the City Government effectively produces two kinds of homosexuality. One is characterised by class-bound practices of consumption (attendance at commercial gay venues), and 
constitutes the imagined subject of US-inflected minority rights discourses cited by the administration in order to project an image of Taipei as a 'modern, democratic city'. The second kind of homosexuality, by contrast, is seldom spoken of by the administration, save in the often indirect language of the Taipei City Police Department after its periodic spates of harassment and arrest of practitioners of homosex in public places. This is the rather declassé kind of homosexuality, whose subject is imagined not to be a 'white-collar worker' but rather to be a student or unemployed, and to utilise free, public space for the practice of his sexuality, rather than commercial leisure spaces. For the City Government, this second, unauthorised kind of homosexuality cannot be the subject of the liberal language of 'gay rights' (see He Chunrui 1997). In what follows I will explore in more detail this underlying conflict between the City Government's representations of New Park as signifier of modern, democratic Taipei, and tongzhi representations of it as a 'homosexual' site, through a consideration of the effects of the reconfiguration of the categories 'public' and 'private' in Chen's Taipei.

\section{'Public/Private' Reconfigured}

The epistemology which divides spaces into those associated with family, property, intimacy, sexuality, and reproduction (the 'private') and those associated with the political, the state, citizenship, rationality, and production (the 'public') has long stood as a central organising system of Western modernity (Duncan 1996b) [9]. These historically entrenched social categories of public/private are also inscribed in geographic space: the home of the normative, heterosexual family is the archetypal 'private' space, and the world of commerce and politics situated outside the home, in the street, the shop, and the workplace, is by contrast 'public' space. EuroAmerican anti-homophobic work has been quick to point out the problems inherent in such a spatial and conceptual distinction for sexually non-normative subjects. Primary among these problems is the relegation of 'sexuality' to the realm of the private and hence the presumptively apolitical (see Duncan 1996b). Further, the 'public sphere' projected by liberal discourse is never as neutral or disembodied as it claims to be, typically representing the interests not of a truly reflective 'public' but rather those of a masculine, white, middle-class, heterosexual subject [10]. Hence, the problem facing those who fail to conform to this standard is now seen not so much as one of simply seeking inclusion in this limited realm, as one of redefining the meaning of the 'public' itself with reference to the assumedly 'private' subjects of gender and sexuality [11]. In addition, the 'private' realm of the heterosexual family and home can be understood to reproduce sexual ideologies that are fully political in character, and which should thus properly be considered as part of a wider, 'public' realm (Duncan 1996b). It comes as no surprise, then, that much anti-homophobic work which addresses the social production of space has sought to problematise the public/private divide, which in liberal usage tends to place 'homosexuality' in an impossible position as always either 'irrelevant', because properly private, or obscene, because improperly public (see, for example, Duncan 1996b; 
Bell 1995; Berlant \& Warner 1998; Foucault 1978; Munt 1995; Knopp 1995; Weeks 1998; Bech 1998; Leap 1999).

Wu Guangting observes that Chinese cities in dynastic times lacked the kind of public space found in European cities in squares and parks. Such putatively 'public' spaces were added by European colonisers to coastal treaty-ports in the nineteenth century-but remained barred to the colonised population (Wu 1996: 106-107; see also Young 1990: 108; Knopp 1995: 154-159 on the development of 'public' spaces in Euro-American cities since the eighteenth century). Similarly, he notes, when the Japanese colonial government completed the construction of what is now the Presidential Palace in Taipei in 1919, the large 'public' square in front of it was in fact an expression of colonial domination, whose use was completely controlled and orchestrated by the Japanese colonisers (Wu 1996: 106). This observation also applies to a great degree to New Park itself, which was built by the Japanese in the city's central district-populated mainly by Japanese rather than Taiwanese-for their own "leisure-time enjoyment (Lai 1997) [12]. When the "KMT occupation replaced the Japanese one in the late 1940s, the control of the square was taken over by the KMT with very little change in the way this highly 'official' public spacenow part of the militarised Bo'Ai Special District-was experienced by the local population (Wu 1996: 106-107). Thus, according to $\mathrm{Wu}$, until the political and social liberalisations of the late 1980s, 'public space' was neither a conceptual nor an experiential reality in Taipei City.

While for Euro-American writers the 'public/private' divide of social and architectural space is such an entrenched ideology as to provide a self-evident object of feminist and anti-homophobic critique, in Taiwan the project of creating non-state 'public' space (as a concept, a discursive realm and an architectural product) is one which it has been possible to address seriously only in the past 10-15 years [13]. The City Government's populist rhetoric on the 'citizens' city' can be read precisely as an attempt to install a notion of the city as 'public' place, determined not by the state but rather by this new entity of the 'city' and 'citizens' themselves. This project of making newly 'public' the city's spaces is nowhere more evident than in the plan to redesign the Presidential Square and the adjoining New Park as democratised spaces for Taipei's 'citizens'.

David Bell (1995) suggests that the public homosexuality enacted in cruising practices becomes the focus of heightened social anxiety in Britain partly due to the ways in which it refigures or shifts the long-entrenched divide between the public spaces of citizenship, and the private spaces of intimacy [14]. As I have suggested, a major aspect of the Taipei City Government's reimagining of 'Taipei City' as shimin chengshi is its attempt to install a newly 'public' space. Yet clearly, this newly 'public' space has limits, to which certain forms of public, non-consumptive sexual practice like homosexual cruising lie close, while other forms of tongzhi leisure practice such as the attendance at privately run bars is the subject of considerably less anxiety [15]. I want to propose that this may be because the new notion of public space also installs a corresponding 'private space', and consequently also something like the stubborn demarcation between public and private which Bell describes. In this way, spaces of 'citizenship' come to exclude forms of behaviour 
which are consigned to the realm of the 'private' in the interests of constructing a 'global' city and the appropriate spatial practices for it.

In late July 1997, the Taipei City Police Department launched an apparently carefully orchestrated campaign of harassment on tongzhi cruising on Changteh Street, adjacent to New Park. Responses by the Taipei City Police Department to tongzhi protest following the Changteh Street incident focus on the threat which the presence of the nocturnal non-waged at large in the city poses to the city's vision of middle-class respectability. This threat is represented in the particularly extravagant statement by the Taipei Police which follows, as endangering the 'peace' of the 'residents':

The evidence collected suggests that scores of homosexuals often gather in the deep of the night, and sit, pair by pair, on New Park's railings [...] drinking and causing uproar and clamour the whole night long, disturbing the residents' (jumin) peace. (Taipei Police Department spokesperson, quoted in Lin 1998: 22)

Lin Hsien-Hsiu points out that there are in fact no residents in Changteh Street nor anywhere near it who might be 'disturbed' by the homosexuals (Lin 1998: 22). This perhaps makes only more significant the fact that it is proper 'residents' who would use the night hours for quiet 'private' activities, whose peace is purportedly disturbed by the homosexuals, whose major offence is their alleged public drunken hilarity. If no such 'residents' exist in reality, their notional domesticity is so crucial to the new spatial ideology that they may be conjured specifically in order to pose a contrast to the non-resident homosexuals. In this statement, it is specifically the quiet privacy, rather than the sexuality, of proper 'residents' which is challenged by the noisy public-ness of this particular form of 'homosexuality'. Further, as Berlant and Warner point out in their discussion of the 'fantasy' of urban locale defined by residence rather than also by transient inhabitation of public space, the invocation of 'residents' assumes 'a community of shared interest based on residence and property', thus inscribing clear class-bias against non-property-owning inhabitants of a given locale (Berlant \& Warner 1998: 563). Importantly, Berlant and Warner add that

It is not because of a fluke in the politics of zoning that urban space is so deeply misrecognised [as belonging only to property-owners]; normal sexuality requires such misrecognitions, including their economic and legal enforcement, in order to sustain its illusion of humanity. (Berlant \& Warner 1998: 563-564)

I am suggesting that it is precisely the system which Berlant and Warner describe here, in which the right to the city is in reality limited to the property-owning middle class, and in which 'normal sexuality' is also the preserve of this same propertied, middle-class subject, which is now reproduced in Taipei as the City Government installs a notionally 'public', hence also a newly 'private' space. In the liberal ideology reproduced by Chen's urban planning policies, 'humanity' equates to a particular class position; thus whilst in the excerpt above, 'homosexuals' are denied 
the right to public space, the logic of this ideology suggests that the problem is less their sexuality per se than their lack of 'resident' status or their failure adequately to enact the spatial performance of the 'resident', which involves upholding the separation of the spaces of intimacy (private housing) from those of citizenship (public spaces of street and park).

If it is tempting to celebrate the liberal rhetoric of Chen's City Government in contrast to the overtly homophobic nationalisms espoused by other regimes in the region, it is nevertheless crucial to bear in mind that the reproduction of liberal ideologies by the DPP is prone also to reproduce some of the exclusions of such a politics as they have been identified in other locations where similar politics have a longer history [16]. Before rejoicing too hastily over the administration's valorisation of 'public' over state space, we might consider the consequent exclusions occurring at the intersection of the determinants of class and sexuality, with direct effects upon those who appropriate the newly 'public' spaces of the city for social and sexual practice.

\section{Tongzhi Counterpublics [17]}

Nevertheless, the reconfiguration of the categories of 'public' and 'private' effected by Chen's City Government may also open the way for effects which exceed that of the privileging of the bourgeois subject. It might be argued, for example, that by constructing new spaces of 'citizen' and 'public', Chen's administration helps facilitate the appearance of critical counterpublics like the public tongzhi movement itself [18]. If the administration attempted to enforce the social spatialisation of the 'private', domestic space of the city's 'residents' in opposition to the 'public', civic space of the 'citizens', the tongzhi movement contests this spatialisation by claiming its own spaces of sexual citizenship [19]. This is precisely what is claimed by the Tongzhi Citizens' Alliance as it asserts the right of sexual dissidents to occupy public space as such.

The questions about 'public' space, 'public' culture, and sexuality which are raised by the City Government's plans for the Bo'Ai Special District resonate through tongzhi-affirmative writing produced throughout the 1990s. A 1994 editorial from the lesbian magazine $A i$ Bao (see Figure 1), for example, enjoins: 'Don't imagine that we have only New Park-have a think; look around you. Any place can become a base in which tongzhi amass and which we claim as our own' ( $A i$ Bao no. 2: 6). These words figure tongzhi as mobile agents moving throughout the urban fabric, claiming and transforming multiple territories in their advance. In this vision, all places are potential 'bases' (judian) for tongzhi whose territory then expands ever further out into the multinucleated tongzhi city. Similarly, and specifically in response to the City Government's plans for the New Park area, Lin Hsien-Hsiu has written:

The genius of tongxinglian culture arises precisely from its ephemerality and its resilience. [...] When New Park becomes a 'bright', 'healthy' recreational space and train station for normal people, homosexuals can speak 
Figure 1 Cover of Taiwanese lesbian magazine Ai Fu Hao Zizai Bao [Ai Bao, Love Paper], Issue 2, June 1994. Artwork by Apple (courtesy of the artist and $A i$ Bao editors). The text below the image reads: 'She hates making boyfriends,/Welcoming girlfriends:/The Mystic Girl-Dragon, adrift in the bitter seas of strange lands./I'm not a young lady/What I am is a girl-demon./Merciless circumstance forces me down to the city of darkness'

out, saying: it's no fun here, I'm not hanging around. I'm going somewhere else. (Lin 1997: 59)

Lin's words demonstrate how a tongxinglian defined by its mobility can work as part of a tongzhi imaginary which privileges marginality and a refusal to be defined by the institutions of the 'normal'. At the same time, this urban tongzhi imaginary figures the city as written over and permeated by the signs of tongzhi presence. Arriving at a comparable formulation, in her study of the 'symbolic city' which provides the context for the imaginary of the ' $\mathrm{T}$ bar' (lesbian bar), anthropologist Antonia Chao analyses a statement made by one of her interviewees. The woman relates: 'We quannei ren ("people within the circle": lesbians) are all over the city. Wherever I go, I see quannei ren all over the place' (Chao 1996: 49). Chao interprets the city projected by this woman's statement:

What [the above] assertion [...] identifies is a distinct type of subject-one that is intended to be and normally is immediately recognised as such by a discerning agent, that is, another quannei ren. This form of identificatory 
interlocution is assumed to occur only in the 'city'. [...] The 'city' is visualised as a stage on which one's identity is then reconfirmed over time through unspoken, vicarious identificatory acts. (Chao 1996: 50, emphasis in original)

The image of the 'city' of quannei ren conjured by this interviewee is a vision of the constant co-presence of quannei ren within the city, which is defined by its function as a 'stage-like metropolitan space in which the exchange of quannei identity takes place' (Chao 1996: 51). This example, too, shows a reading of public, urban space as the staging-ground for forms of sexual identity and practice which exceed the model of the bourgeois, consuming subject privileged in the City Government's version of the city. In the urban imaginaries projected by the Ai Bao editorial, Lin's article, and Chao's interviewee, the tongzhi city is defined by an abiding tongzhi co-presence within the public spaces of 'citizenship' in the city.

\section{Conclusion}

I argued in the first part of this paper that the moment in which a liberal democratic politics gains ascendancy over the authoritarian nationalism of the old-style KMT leaves disenfranchised social groups vulnerable in new ways to the class- and sexuality-based exclusions of liberal humanism. Nevertheless, that same moment also enables the new forms of political mobilisation which contest such exclusions. The result, I suggest, is that the public/private demarcation which characterises modern bourgeois societies becomes entrenched at the same moment as do the conditions for its contestation [20]. While Chen's administration struggled to cordon the 'public' spaces of citizenship off from the 'private' spaces of sexuality, the Tongzhi Citizens' Alliance and other tongzhi publics respond in the same moment with an insistence that sexuality be understood as a public question, and that the politics of intimacy be thought of in the same breath as citizenship. Simultaneously, they go about the business of constructing counterpublic spaces which provide alternatives to the exclusionary official spaces of the city and state, and at the same time effect the ongoing critique of their very principles of organisation.

Rather than precipitating the passage of tongxinglian into some zone of final 'liberation', free from the constraints imposed upon it in the past and within other states in the region, the transformation in official discourses on sexuality in 1990s Taiwan means only that tongxinglian is now regulated in new and different ways. But the reconfiguration of the spaces of nation and city; private and public in this period, also marks the point at which new contestatory possibilities open up to those who organise in resistance to Taiwan's emergent liberal regime of sexual and social regulation.

\section{University of Melbourne}

\section{Notes}

All translations from Chinese to English cited in this paper are my own unless otherwise specified.

[1] See Berry (1994: 69-104) for a further discussion of the abjection of homosexuality in the 
public discourses of the PRC and Singapore. See also Heng and Devan (1992) on Singaporean nationalism.

[2] For a discussion of the positioning of tongxinglian as both a security and a cultural threat to the Republic of China during the martial law period, see Chao (1996) especially Introduction and chapter II.

[3] For histories of Taiwan's tongzhi movement, see Zheng Meili (1997) and Yuanyuan Chuanbo (1996).

[4] The term tongzhi arrived from Hong Kong in 1992 as part of the Chinese translation for a 'New Queer Cinema' section in Taipei's annual Golden Horse Film Festival (Xiao Wenhui 1994).

[5] Laws used to prosecute those showing homosexual behaviour in public include the criminal law code's article criminalising behaviour which are 'deleterious to custom' (fanghai fenghua zui), and the article which criminalises behaviour 'deleterious to fine traditions' (fanghai shanliang fengsu) in the Laws for the Protection of Social Order (Zhang Zhiben \& Lin Jidong 1996, Criminal Law Article 16: 340; Social Order Law Article 2, Clauses 80-84: 555).

[6] Many thanks to Steve Bradbury for generously sharing with me his extensive archive of Taiwanese press clippings on Ang Lee and The Wedding Banquet.

[7] While there are of course important differences between DPP and KMT ideology, this paper assumes that key aspects of the liberal politics espoused by Mayor Chen Shuibian and the DPP in the 1990s are echoed in the political and cultural ideology of the new-style Kuomintang under Lee Teng-Hui, and vice versa. This is clearly the case in relation to the vision of both the KMT and the DPP of a 'global' Taipei City in line with the KMT's economic strategy for the island as a whole as laid out in the 'Asia Pacific Regional Operations Centre Plan'. On the APROC Plan, see Chu-Joe Hsia (1995: 57-102) and Chen Shuibian's interview with You Changshan, in which Chen speaks of his vision for Taipei specifically in relation to the APROC Plan (You Changshan 1998: 104-106).

[8] While the winning designs in the island-wide competition to redesign the space have never been synthesised and implemented, as was the original plan, New Park as a site of public homosex is now threatened none the less by the building of a major Mass Rapid Transit station at its south-east corner. This means that after dark the park becomes a thoroughfare for large numbers of commuters. As Chih-Hung Wang notes, the MRT project-relatedly to Chen's Historical Capital District Preservation project-speaks of the desire of the New Taiwan' being constructed in this period to embrace strategies of internationalisation, modernisation, and technologisation (Chih-Hung Wang 1996). The impact of the MRT station on cruising in the park would warrant a separate investigation and discussion; unfortunately, such a discussion is beyond the scope of this paper.

[9] On the historical production of the 'private', see also Armstrong (1987); on sexuality and the private, see Foucault (1978).

[10] For an elaboration of the exclusions necessitated by the ideal of impartiality and the related conception of the civic public sphere, see Young (1990), esp. chapter 4. See also Duncan (1996a: 2).

[11] See Grosz (1994). It is one of Grosz's primary aims in this work to problematise the Cartesian mind/body dualism which is central to the gendered division of subjects and spaces into public and private.

[12] Lai's thesis, submitted to Tamkang University's graduate school of architecture, performs a very thorough historical documentation of the history of New Park as a social centre for male tongzhi. The emphasis of the work is upon the cultural significance of the site to male tongzhi based on their collective memory of its history as a site of homosexual identification and practice.

[13] On the traditional subsumption of social space by the rubric of 'family' in the language of 'jiating/jiawai' (family/outside the family), see Chang Hsiao-Hung and Wang Chih-Hung (1995: 115). The life-spaces of jiating/jiawai are of course markedly gendered. The ideal of 
'nanzhu wai; nü zhu nei' ('the man's domain is outside; the woman's inside [the jia]') demonstrates a conflation of the feminine with the domestic comparable to that criticised in Euro-American feminist writings. The gendering of Taiwan's urban spaces is also a topic frequently addressed in the literature of Taiwan's feminist movement (see, for example, Yang Changling 1997: 47-51); unfortunately, a detailed discussion of these questions is beyond the scope of this paper.

[14] It does this both by placing sexual practices-supposedly 'private' acts-in public places, as well as by challenging dominant notions of 'intimacy' itself as defined by heteronormative monogamy (Bell 1995; Duncan 1996b).

[15] That the administration has less objection to the attendance of tongzhi bars and clubs is illustrated by its offer to provide a tongzhi club to compensate for the loss of the public space of New Park (see Lin Shuling 1996a).

[16] Cf, Iris Marion Young's critique of the 'universal citizen' representative of the civil public spheres of the USA and Europe (1990: 110-111).

[17] 'Counterpublics' is Berlant and Warner's term (1998: 558-564).

[18] Lawrence Knopp's account of some of the contradictions of Western urban modernities which provided the conditions for the contestation of the heterocentric and rigidly gendered and raced coding of space in the new industrial cities (1995: 154-159).

[19] The term 'sexual citizenship' is used by both Jeffrey Weeks (1998) and by David Bell (1995).

[20] Jeffrey Weeks writes that the 'sexual citizen', in claiming a public identity which is defined by the presumptively private attribute of a particular sexuality, 'is a hybrid being, breaching the public/private divide' (1998: 36 ).

\section{References}

Armstrong N 1987 'The rise of female authority in the novel', in her Desire and Domestic Fiction: a Political History of the Novel Oxford Oxford University Press.

Bech H 1998 'Citysex: representing lust in public', Theory, Culture and Society 15 3-4 November 215-241.

Bell D 1995 'Perverse dynamics, sexual citizenship and the transformation of intimacy', in D Bell \& G Valentine (eds) Mapping Desire: Geographies of Sexualities London and New York Routledge.

Berlant L \& M Warner 1998 'Sex in public', Critical Inquiry 24 (Winter) 547-566.

Berry C 1994 A Bit on the Side: East-West Topographies of Desire, Sydney EmPress.

Chang Hsiao-Hung \& Wang Chih-Hung 1995 'Taibei Qingyu Dijing' ['Mapping Taipei's landscape of desire'], in Chen Ruxiu \& Liao Jinfeng (eds) Xunzhao Dianyingzhongde Taibei [Focus on Taipei through Cinema 1950-1990] Taipei Wanxiang Tushu.

Chao A 1996 'Embodying the invisible: body politics in constructing contemporary Taiwanese lesbian identities', $\mathrm{PhD}$ dissertation Cornell University.

Duncan N 1996a 'Introduction: (Re)Placings', in N Duncan (ed.) BodySpace: Destabilizing Geographies of Gender and Sexuality London and New York Routledge.

Duncan N 1996b 'Renegotiating gender and sexuality in public and private spaces', in N Duncan (ed.) BodySpace: Destabilizing Geographies of Gender and Sexuality London and New York Routledge.

Foucault M 1978 History of Sexuality, vol. 1 London Penguin.

Grosz E 1994 Volatile Bodies: Toward a Corporeal Feminism St Leonards Allen \& Unwin.

He Chunrui 1997 'Nürende Heiye Xingzou Quan' ['Women's right to be out at night'], paper given at the Conference on the Changteh Street Incident 19 August Taipei.

Heng G \& J Devan 1992 'State fatherhood', in A Parker M Russo D Sommer \& P Yaeger (eds) Nationalisms and Sexualities New York and London Routledge.

Hsia Chu-Joe 1995 'Quanqiu Jingjizhongde Taiwan Chengshi yu Shehui' ['Taiwanese cities and 
society in the global economy'], Taiwan: a Radical Quarterly in Social Studies no. 20 (August) 57-102.

Huang Wenzheng 1997 'Li Zongtong Dang Jinzhu, Li An Bu An La?' ['Ang Lee uneasy at President Lee's offer of sponsorship?'], China Times 13 December 22.

Knopp L 1995 'Sexuality and urban space: a framework for analysis', in D Bell \& G Valentine (eds) Mapping Desire: Geographies of Sexualities London and New York Routledge.

Lai Zhengzhe 1997 'Zai Gongsi Shangban: Xin Gongyuan Zuowei Nantongzhi Huodong Didian zhi Yanjiu' ('Work in company: a research of usage of the New Park by male tongzhi'), MA thesis Tamkang University.

Leap WL 1999 'Introduction', in WL Leap (ed.) Public Sex/Gay Space New York Columbia University Press.

Lin Hsien-Hsiu 1997 'Hebi Liulian Xin Gongyuan?' ['Why carry a torch for New Park?'], in $\mathrm{H}-\mathrm{H}$ Lin Kanjian Tongxinglian [Seeing Homosexuality] Taipei Kaixin Yangguang.

Lin Hsien-Hsiu 1998 'Tian Zheme Hei Feng Zheme Da Baba Zenme Hai Bu Huijia? Wuguan 'Tongzhi Yexing Quan" ' ['The wind's so fierce and the sky's so black how come daddy's still not back? Nothing to do with “Tongzhis' right to be out at night" '], Together no. 110 January 22.

Lin Shuling 1996a 'Beishi Youyi She Gongli Tongxinglian Julebu' ['Taipei City considers publicly funded homosexual club'], China Times 13 January.

Lin Shuling $1996 \mathrm{~b}$ 'Taibei Shi Jiang Jiaqiang yu Tongxinglian Tuanti Lianji' ['Taipei City Government to strengthen links with homosexual groups'], China Times 13 January.

Munt S 1995 'The lesbian Flaneur', in D Bell \& G Valentine (eds) Mapping Desire: Geographies of Sexualities London and New York Routledge.

Patton C forthcoming 'Stealth bombers of desire: the globalization of "alterity" in emerging democracies', in Rethinking Marxism.

Taipei City Government, Department of Urban Development 1996 Urban Development White Paper: Taipei City 1996 Taipei Department of Urban Development.

Wang Chih-Hung 1996 'Taibei Xin Gongyuande Qingyu Dilixue' ['Erotic geographies of Taipei Park'], Taiwan: a Radical Quarterly in Social Studies no. 22 (April) 195-218.

Weeks J 1998 'The sexual citizen', Theory, Culture and Society 15 3-4 November 35-52.

Wilson R \& W Dissanayake (eds) 1996 Global/Local: Cultural Production and the Transnational Imaginary Durham NC and London Duke University Press.

Wu Guangting 1996 'Taiwan Shehui Bianjuande Zhengxuan Huodong' ['The public competition in Taiwan's changing times'], Chinese Architect 261 106-107.

Wu Guangzhong 1997 'Li An, Xue Ge Ni Jinjian Li Zongtong' ['Ang Lee and Sigourney Weaver have an audience with President Lee'], Minsheng Bao 13 December 4.

Xiao Wenhui 1994 'Zhege Ren Feichang Lin Yihua' ['This guy is very Edward Lam'], Eslite Book Review 17 (September) 54-56.

Xie Peijuan 1996 'Xiwang, Kuaile, Yixinglian' ['Hopeful, happy, heterosexual'], Marie-Claire Taiwan no. 36 (February) 89-90.

Yang Changling 1997 'Zai Weichengzhong Bu'an Duxing de Nüren' ['Women who walk alone uneasily in the City of Danger'], Stir no. 4 (June) 47-51.

You Changshan 1998 'Shi Taibei Chengwei Guojicheng' ['Making Taipei into an international city'], Tianxia Zazhi 1 July 104-106.

Young IM 1990 fustice and the Politics of Difference Princeton NJ Princeton University Press.

Yuanyuan Chuanbo 1996 Airen Tongzhi [Tongzhi Lover] Taipei Jin Bolo.

Zhang Zhiben \& Lin Jidong (eds) 1996 Zui Xin Liufa Quan Shu [The Newest Edition of the Six Legal Codes] Taipei Da Zhongguo.

Zheng Meili 1997 Nü'er Quan [The Girls' Circle] Taipei Fembooks. 


\section{University Library}

\section{- M M I N E R VA A gateway to Melbourne's research publications}

Minerva Access is the Institutional Repository of The University of Melbourne

Author/s:

Martin, Fran

Title:

From citizenship to queer counterpublic: reading Taipei's New Park

Date:

2000

Citation:

Martin, F. (2000). From citizenship to queer counterpublic: reading Taipei's New Park.

Commual/Plural: Journal of Transnational and Crosscultural Studies, 8(1), 81-94.

Publication Status:

Published

Persistent Link:

http://hdl.handle.net/11343/34222 